\title{
The Effect of Laser Remelting on the Microstructure and Mechanical Properties of the Bonding Interface in a Hybrid Metal Additive Manufacturing Process
}

Fei Xue ( $\nabla$ xuefei82@xjtu.edu.cn )

Xi'an Jiaotong University

\section{Xin Cui}

Xi'an Jiaotong University

\section{Longfei Zheng}

Xi'an Jiaotong University

\section{Mian Li}

National Innovation Institute of Additive Manufacturing, Xi'an Shaanxi

\section{Xuewei Fang}

National Innovation Institute of Additive Manufacturing, Xi'an Shaanxi

\section{Research Article}

Keywords: Laser remelting, Wire arc additive manufacturing (WAAM), Laser metal deposition (LMD), Bonding interface, Surface profile

Posted Date: June 17th, 2021

DOl: https://doi.org/10.21203/rs.3.rs-600261/v1

License: (c) (1) This work is licensed under a Creative Commons Attribution 4.0 International License. Read Full License 


\title{
The effect of laser remelting on the microstructure and mechanical properties of the bonding interface in a hybrid metal additive manufacturing process
}

\author{
Fei Xue, Xin Cui, Longfei Zheng, Mian Li, Xuewei Fang \\ Corresponding author's email address: xuefei82@xjtu.edu.cn
}

\begin{abstract}
Affiliations
School of Mechanical Engineering, Xi'an Jiaotong University, Xi'an Shaanxi

Fei Xue, Xin Cui, Xuewei Fang

National Innovation Institute of Additive Manufacturing, Xi'an Shaanxi

Longfei Zheng, Mian Li
\end{abstract}

\begin{abstract}
In order to realize both high-efficient forming with the wire arc additive manufacturing (WAAM) and precise forming with the laser metal deposition (LMD) for some complex-structure and highprecision parts, a hybrid metal additive manufacturing method is proposed. The part is decomposed into sub volumes, then the sub volumes with relatively simple-structure features are formed through WAAM as a substrate, and the other sub volumes with more complex-structure or small-sized features are formed through LMD on the former substrate. However, the mechanical properties of the bonding interface would be reduced, if the later sub volumes are directly deposited by LMD on the rough WAAM substrate surface. In order to avoid unnecessary machining process between WAAM and LMD for high efficiency, and ensure the mechanical properties of WAAM-LMD bonding interface the laser remelting method is applied for improving the profile of WAAM substrate surface. The simulation model of heat transfer and fluid flow in the laser remelting process is established, the influence of the laser power and the scanning speed on the surface-profile improvement is researched by simulation and verified by experiments, Based on that the remelting process parameters are optimized. Furthermore, based on the WAAM formed substrate, the LMD formed volumes are deposited directly, after surface milling and after laser remelting, respectively. Then the microstructure and the mechanical properties of the bonding interface are compared among the three process methods, the feasibility of the laser remelting method for improving the bonding interface performance is verified.
\end{abstract}

\section{Keywords}

Laser remelting; Wire arc additive manufacturing (WAAM); Laser metal deposition (LMD); Bonding interface; Surface profile 


\section{Introduction}

The wire arc additive manufacturing (WAAM) and the laser metal deposition (LMD) are two typical metal additive manufacturing processes with different heat source and raw material morphology. WAAM is more suitable for forming relatively simple-structure and large-sized parts due to its low material cost and high deposition efficiency. However, with the higher heat input during the forming process, the shape of molten pool is difficult to control. Therefore, the surface profile and the accuracy are relatively poor [1-2]. On the contrary, LMD is more suitable for forming complexstructure and high-precision parts due to its lower heat input and relatively well control of the molten pool shape during the forming process. However, the material cost is higher and the deposition efficiency is lower. In order to realize both high-efficient forming with WAAM and precise forming with LMD for some complex-structure and high-precision parts, a hybrid metal additive manufacturing method is proposed. The part is decomposed into sub volumes, then the sub volumes with relatively simple-structure features are formed through WAAM as a substrate, and the other sub volumes with more complex-structure or small-sized features are formed through LMD on the former substrate.

The microstructure and the mechanical properties are both different between the parts formed by WAAM and LMD [3-4]. Take 316L stainless steel as an example, which is widely used in petroleum, petrochemical, aerospace, nuclear energy, and other industries due to its strong corrosion resistance [5-6], several researches have been carried out about its additive forming properties by different processes. Hammar $\mathrm{O}$ et al. [7-8] found the $\mathrm{Cr} / \mathrm{Ni}$ equivalents ratio in 316L stainless steel determines the solidification mode in the equilibrium state. CMT is a typical technology for WAAM, Wang Xiaoguang et al. [9-10] found that the microstructure of 316L stainless steel parts formed by CMT is composed of $\gamma$-austenite and $\delta$-ferrite, the amount of $\delta$-ferrite increases with the increase of interlayer temperature, and the tensile strength increases with the decrease of interlayer temperature, Jia Wenpeng et al. [11-12] formed 316L stainless steel parts by LMD, the microstructure is mainly composed of columnar dendrites, and exhibits $\gamma$-austenite structure. Therefore, if the volumes are formed by LMD on the CMT formed substrate, the microstructure will obviously evolve at the CMT-LMD bonding interface.

On the other hand, the profile of CMT substrate surface is sometimes too poor to form later volumes directly by LMD. Generally, it is necessary to improve the surface profile of CMT substrate through milling, and then go on to form later volumes by LMD, however, the efficiency is difficult to improve. In order to avoid unnecessary milling, the laser remelting method for improve the profile of CMT substrate surface is researched in this paper. Because the curvature radius on the substrate surface is variable, the liquid molten pool will flow to the adjacent position with larger curvature radius, then the substrate surface will be flatten after the laser remelting [13-14]. The current researches around the laser remelting technology are mainly focused on the parameter optimization 
and the performance evolution. Meng Yunlong et al. [15-17] proposed that the crystal morphology mainly depends on the parameter $\mathrm{T} / \mathrm{G}$ ( $\mathrm{T}$ is the temperature gradient, $\mathrm{G}$ It is the ratio of the solidification rate) in the laser remelting process, and the increase of cooling rate makes the crystal grains smaller and the microstructure denser. YAO O et al. [18-23] investigated the effect of laser remelting on the surface performance strengthening besides the surface finish improving, the corrosion resistance and the wear resistance on the remelten surface are also improved.

Aiming at the $316 \mathrm{~L}$ stainless steel, the simulation model of heat transfer and fluid flow in the laser remelting process is established in this paper, and the remelting process parameters are optimized. Based on the WAAM formed substrate, the LMD formed volumes are deposited directly, after surface milling and after laser remelting, respectively, the microstructure and the mechanical properties of the bonding interface are compared among the three process methods, the feasibility of the laser remelting method for improving the bonding interface performance is verified.

\section{Simulation}

\subsection{Establishment of simulation model}

\subsubsection{Assumption}

The final surface morphology after laser remelting largely depends on the fluid flow on the free surface during the remelting process. Therefore, based on the basic theories of heat transfer and fluid mechanics, the laser remelting process model is established by multi-physics coupling finite element method to simulate the flow of the molten pool and the formation of free surfaces. The effects of surface tension and the Marangoni convection during the remelting process lead to the improvement of the WAAM substrate surface profile. In order to make the simulation results easy to converge and simulate the laser remelting process more accurately, this model makes the following assumptions on the premise of ensuring that the main characteristics of the actual remelting process are reflected:

(1) The remelted substrate material is considered to be an isotropic and uniform medium;

(2) The material's specific heat, thermal conductivity, density, heat transfer coefficient and other thermophysical parameters change with temperature;

(3) The flow in the molten pool is considered to be viscous incompressible flow;

(4) The laser incident energy distribution is assumed to be an ideal Gaussian distribution;

(5) Consider the heat radiation and heat convection of the substrate;

\subsubsection{Main control equations}

The transient temperature field is controlled by Fourier's law, and the energy conservation equation is as follows [24]:

$$
\rho C_{p}^{*} \frac{\partial T}{\partial t}+\nabla \cdot(-k \nabla T)+\rho C_{P} \mathbf{u} \cdot \nabla T=Q
$$

Where $\rho C_{p}^{*} \frac{\partial T}{\partial t}$ is the heat accumulation term, $\nabla \cdot(-k \nabla T)$ is the heat conduction term, $\rho C_{P} \mathbf{u} \cdot \nabla T$ 
is the heat generated by the flow, $Q$ is the laser heat source term, $\rho$ is the density, $t$ is Time, $k$ is the thermal conductivity, $\mathbf{u}$ is the fluid velocity vector calculated according to the Navier-Stokes equation, as shown below [25]:

$$
\rho \frac{\partial u}{\partial t}=-P \nabla+F_{b}+F_{g}+\mu \nabla^{2} \mathbf{u}
$$

Where $P$ is the pressure in the fluid, $F_{b}$ is the buoyancy, $F_{g}$ is the gravity, and $\mu$ is the dynamic viscosity. For incompressible flow, the fluid continuity equation can be simplified as [25]:

$$
\nabla \cdot(\rho \cdot u)=0
$$

When the solid phase absorbs heat and melts into a liquid, the absorbed heat becomes latent heat of phase change, and the specific heat capacity of the material changes with the change of the phase.

The equation to correct the change of thermal melting $C_{p}^{*}$ with time is [26]:

$$
C_{P}^{*}=L_{m} \frac{\mathrm{d} f_{L}}{\mathrm{~d} T}+C_{P}
$$

In the formula, $T$ is the temperature, $C_{P}$ is the heat capacity, $L_{m}$ is the latent heat of melting, $f_{L}$ is the liquid fraction, which increases in a linear manner, and its expression is shown as [27]:

$$
f_{L}\left\{\begin{array}{lr}
0 & \left(T \leq T_{S}\right) \\
\frac{T-T_{S}}{T_{l}-T_{S}} & \left(T_{S} \leq T \leq T_{S}\right) \\
1 & \left(T_{l} \leq T\right)
\end{array}\right.
$$

In the formula, $T_{S}$ is the solidus temperature of the material, and $T_{l}$ is the liquidus temperature of the material.

\subsubsection{Remelted substrate model}

Aiming at the surface and interface morphological characteristics of CMT forming, a sine curve is fitted as a CMT forming substrate model, with a peak value of $0.2 \mathrm{~mm}$ and a period of $2 \mathrm{~mm}$. As shown in Figure 1, the laser beam is scanned from left to right along the $\mathrm{X}$ axis. The boundaries 4 , 5 , and 6 are non-slip walls during the remelting process.

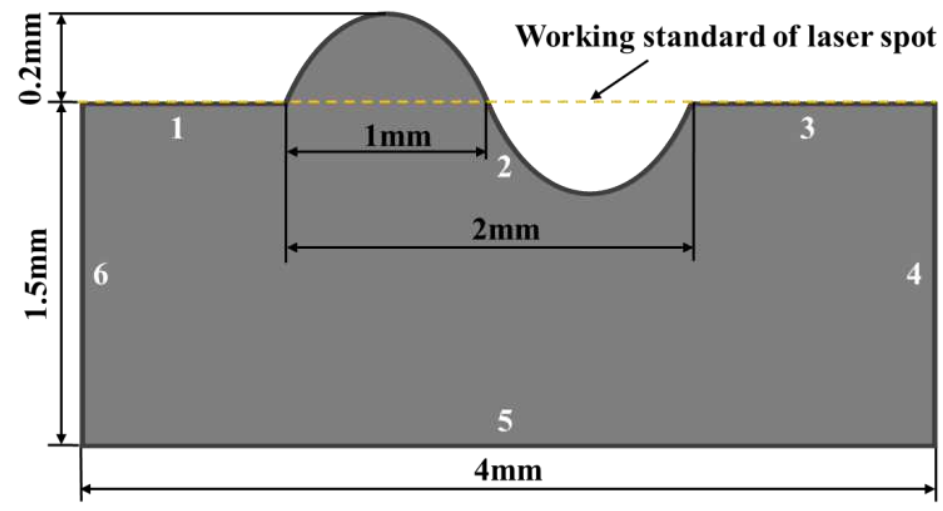

Fig 1 Surface interface model of CMT forming substrate

\subsubsection{Heat source model}

The laser used is a fiber laser, the spot diameter is set to $2 \mathrm{~mm}$, the laser absorption rate is 0.36 , and the laser beam energy is a standard Gaussian distribution. Figure 2 shows the laser energy distribution when the laser power is $900 \mathrm{~W}$. 


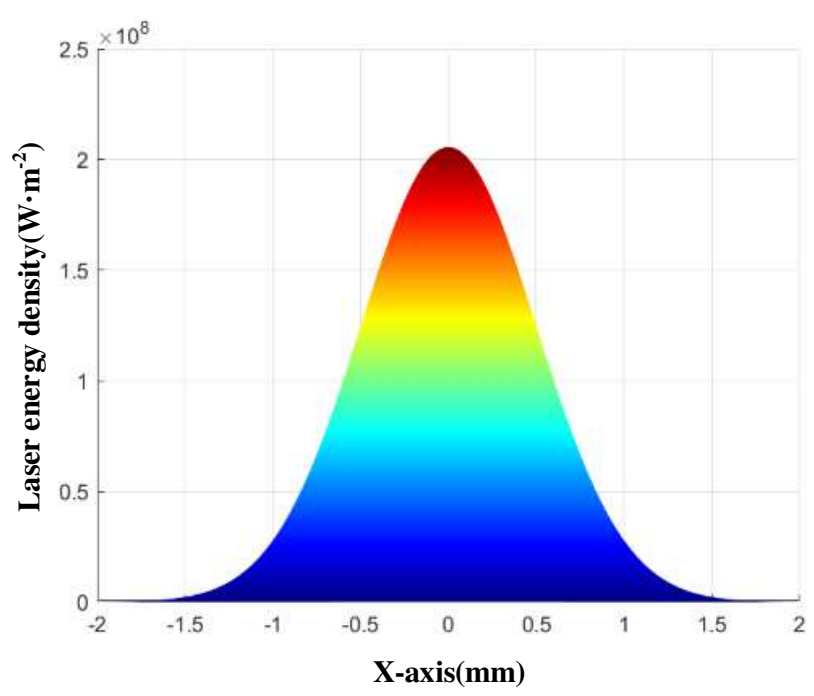

Figure 2 Laser energy distribution diagram at $900 \mathrm{~W}$ laser power

The expression of laser heat flux I is shown in the following formula [28]:

$$
\begin{gathered}
I=\frac{2 P A}{\pi r_{c}^{2}} \mathrm{e}^{-\frac{2 r^{2}}{r_{c}^{2}}} \\
r=\sqrt{\left(x-x_{0}\right)^{2}+\left(y-y_{0}\right)^{2}}
\end{gathered}
$$

In the formula, $P$ is laser power, $A$ is laser absorptance, $r_{c}$ is beam radius, $r$ is distance from the current calculation unit to the heating center, $x_{0}$ is spot center $\mathrm{X}$-axis coordinate, $y_{0}$ is spot center Y-axis coordinate.

\subsubsection{Heat transfer boundary conditions}

The heat transfer state of all boundaries of the geometric structure is marked as shown in Figure 3. Due to the boundary conditions of heat conduction, heat convection and heat radiation on the upper boundaries 1, 2, and 3, the boundary condition equations are as follows [29]:

$$
-k \nabla T=\alpha I+h\left(T-T_{a}\right)+\varepsilon \sigma\left(T^{4}-T_{a}^{4}\right)
$$

Where $\alpha$ is the absorption rate of the material, $h$ is the natural convection coefficient, $\varepsilon$ is the emissivity, $\sigma$ is the Boltzmann constant, and $T_{a}$ is the ambient temperature. The expression of the laser heat flux $I$ of Gaussian distribution is [30]:

$$
I=\frac{2 P}{\pi r_{c}^{2}} \mathrm{e}^{-\frac{2 r^{2}}{r_{c}^{2}}}
$$

Where $P$ is the laser power, $r_{c}$ is the beam radius, and $r$ is the distance from the current calculation unit to the heating center.

Boundaries 4, 5, and 6 are only affected by thermal convection and thermal radiation. Therefore, the boundary condition formula is as follows:

$$
-k \nabla T=h\left(T-T_{a}\right)+\varepsilon \sigma\left(T^{4}-T_{a}^{4}\right)
$$

\subsubsection{Laminar flow boundary conditions}

The boundaries 1,2, and 3 are set as open boundaries, and the surface can be freely deformed. On the surface, the surface tension acts along the normal direction, while the Marangoni effect acts along the surface tangential direction [31]. 
Normal:

$$
\sigma_{n}=\kappa \gamma \cdot \mathbf{n}
$$

Tangential:

$$
\sigma_{t}=\frac{\partial \gamma}{\partial T} \nabla_{s} T \cdot \mathbf{t}
$$

Where $\kappa$ is the curvature of the surface profile, $\nabla_{S} T$ is the temperature gradient along the surface tangential direction, $\gamma$ is the surface tension, and $\mathbf{n}$ and $\mathbf{t}$ are the unit normal vector and tangent vector of the local surface respectively.

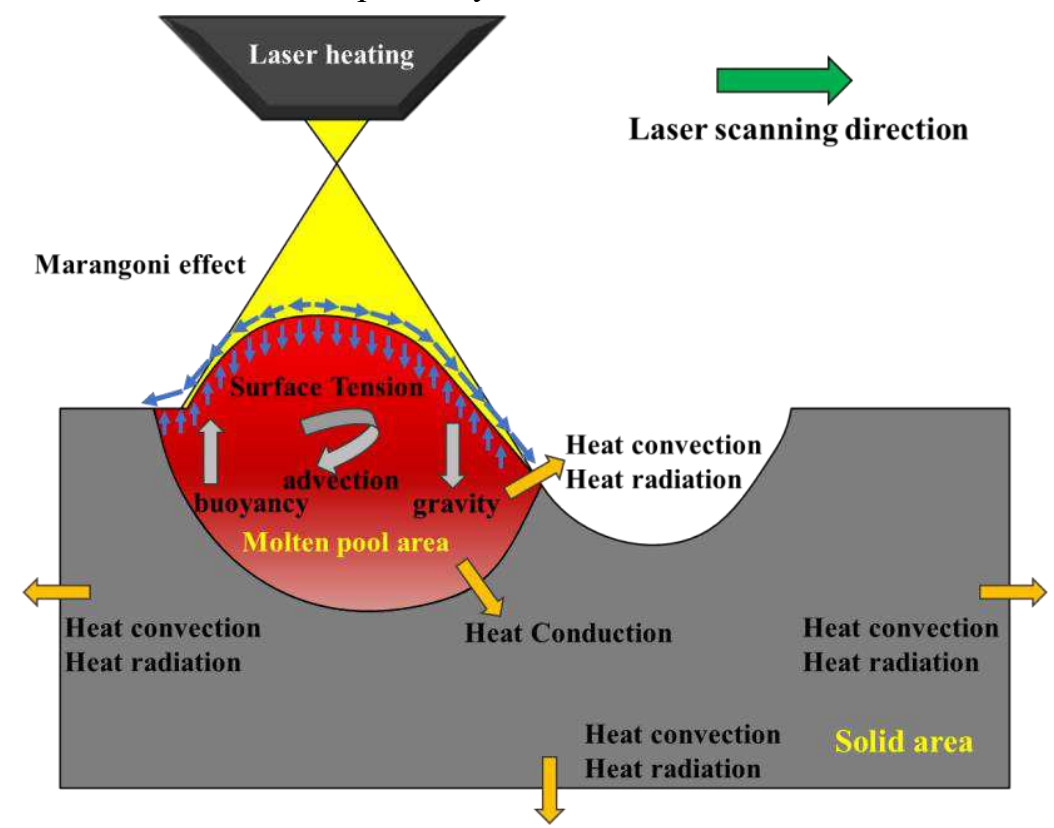

Figure 3 Schematic diagram of the physical field application of each boundary

\subsubsection{Moving grid}

Boundaries 4 and 6 are fixed in the $\mathrm{X}$ direction and boundary 5 in the $\mathrm{Y}$ direction, so the displacement is zero. The ALE method is used to simulate the deformation of the free surface. In this method, the displacement of boundary nodes is determined by fluid dynamics. The domain nodes are described by Euler, and the boundary nodes are described by Lagrangian. In this paper, Laplace smoothing method is used for calculation [32], the coupling equation of ALE and fluid flow is:

$$
V_{m} \cdot \mathbf{n}=\mathbf{u} \cdot \mathbf{n}
$$

$V_{m}$ is the grid velocity, $\mathbf{u}$ is the material velocity calculated according to the liquid fraction expression.

\subsubsection{Mesh division and calculator configuration}

The calculation area is meshed with free triangular elements. In order to reduce the amount of calculation without affecting the precise calculation of the top surface deformation, the curve boundary (boundary 2) is meshed with a custom cell, and the minimum cell size is set to $0.001 \mathrm{~mm}$. In order to simulate the deformation of the free surface, automatic remeshing technology is used. The complete grid consists of 48701 area elements and 2427 boundary elements. The fully meshed 
geometry is shown in Figure 4. The direct solver used for the simulation is PARDISO, and the time required for the laser scanning speed to pass $1 \mathrm{~mm}$ is set as the study time.

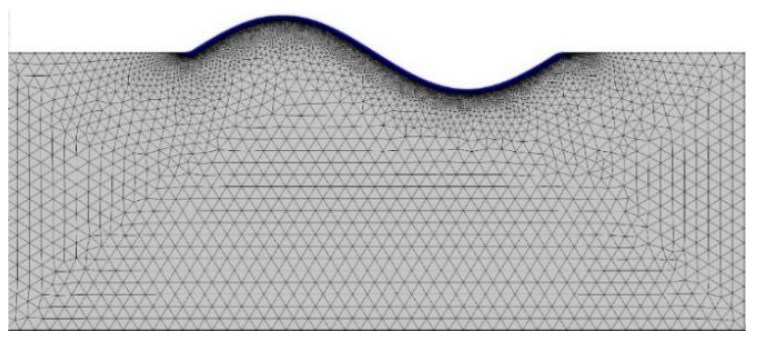

Figure 4 Geometric meshing

\subsubsection{Material properties}

In the simulation model, the substrate is $316 \mathrm{~L}$ stainless steel as an example. Some of the thermophysical parameters and related parameter settings of this material are shown in Table 1. At the same time, the thermal conductivity $k$, specific heat capacity $C \mathrm{p}$, and density rho of $316 \mathrm{~L}$ stainless steel are greatly affected by temperature. The changes of each parameter with time are shown in Table 2.

Table 1316L stainless steel material properties and related parameters

\begin{tabular}{ccc}
\hline Material properties & Unit & Value \\
\hline Solidus temperature & $\mathrm{K}$ & 1693 \\
Liquidus temperature & $\mathrm{K}$ & 1733 \\
Latent heat of fusion & $\mathrm{J} \cdot \mathrm{kg}^{-1}$ & 275 \\
dynamic viscosity & $\mathrm{Pa} \cdot \mathrm{s}$ & $5.3 \mathrm{e}^{-3}$ \\
Thermal expansion coefficient & $1 \cdot \mathrm{K}^{-1}$ & $1.3 \mathrm{e}^{-5}$ \\
Marangoni coefficient & $\mathrm{Kg} \cdot\left(\mathrm{s}^{2} \cdot \mathrm{K}\right)^{-1}$ & $-3.7 \mathrm{e}^{-4}$ \\
Surface Tension & $\mathrm{N} \cdot \mathrm{m}^{-1}$ & 1.8 \\
\hline
\end{tabular}

Table $2 k, C \mathrm{p}$ and $r h o$ of $316 \mathrm{~L}$ stainless steel at different temperatures

\begin{tabular}{cccccccccccc}
\hline$T /{ }^{\circ} \mathrm{C}$ & 300 & 473 & 573 & 673 & 773 & 873 & 973 & 1073 & 1170 & 1370 & 1500 \\
\hline $\mathrm{C} / \mathrm{J} \cdot(\mathrm{kg} \cdot \mathrm{K})^{-1}$ & 470 & 520 & 540 & 560 & 570 & 590 & 600 & 630 & 640 & 670 & 700 \\
$\mathrm{k} / \mathrm{W} \cdot(\mathrm{m} \cdot \mathrm{C})^{-1}$ & 13.4 & 17.6 & 19.4 & 21.8 & 23.4 & 24.5 & 25.1 & 27.2 & 27.9 & 29.3 & 32.9 \\
$\mathrm{rho} / \mathrm{kg} \cdot \mathrm{m}^{-3}$ & 7980 & 7880 & 7833 & 7785 & 7735 & 7681 & 7628 & 7575 & 7520 & 7411 & 7361 \\
\hline
\end{tabular}

\subsection{Analysis of simulation results}

In this study, a sinusoidal area with a length of $2 \mathrm{~mm}$ and a peak value of $0.2 \mathrm{~mm}$ is selected for simulation analysis. Generally speaking, when the laser interacts with the material, the energy is absorbed by the surface, thereby increasing the surface temperature. Taking laser power of $900 \mathrm{~W}$ and scanning speed of $10 \mathrm{~mm} / \mathrm{s}$ as an example, after remelting with $10 \mathrm{~ms}$, the highest temperature in the area near the highest point of the model reaches $1733 \mathrm{~K}\left(T_{l}\right)$. Over time, the area where the temperature rises above the liquidus temperature gradually expands.

There are two main driving forces for fluid flow: one is the surface tension related to the 
curvature of the surface profile, and the other is the Marangoni effect caused by the temperature gradient along the surface of the molten pool. If the tangential force caused by the temperature gradient cannot overcome the viscous force, the surface tension dominates the molten pool; otherwise, the Marangoni effect becomes the dominant. The direction of Marangoni convection is controlled by the surface tension temperature gradient. For 316L stainless steel, the liquid solute will flow from the center to the surrounding [33-34].
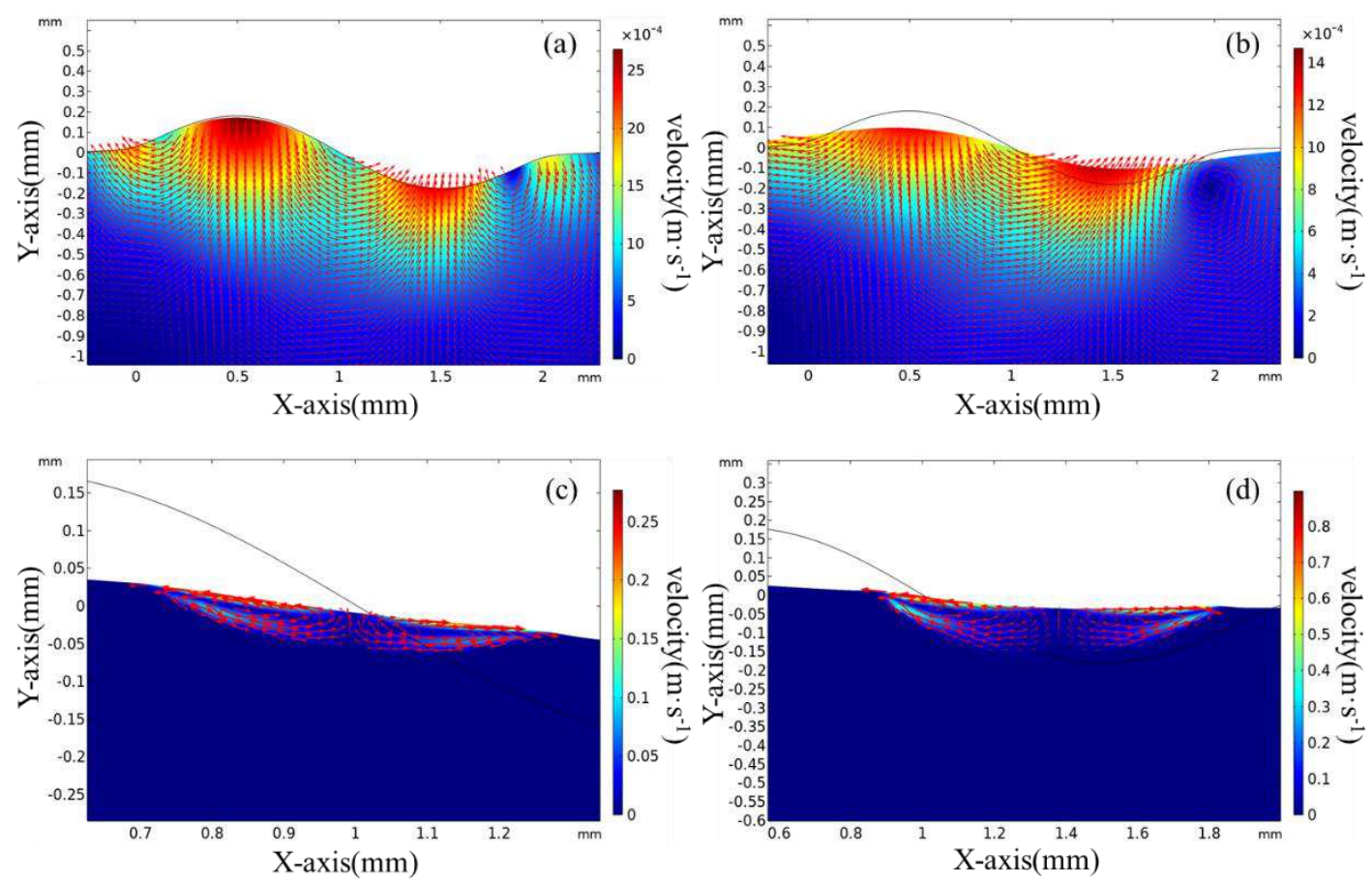

Figure 5 The evolution of the surface velocity field during laser remelting: Time (arrow scale factor): (a) $10 \mathrm{~ms}(32)$, (b) $50 \mathrm{~ms}(60)$, (c) $120 \mathrm{~ms}(0.2)$ and (d) $200 \mathrm{~ms}(0.1)$

Figure 5 shows the evolution of the surface velocity field during the laser remelting process. In the initial stage of melting, the surface tension is first dominated. The molten metal in the peaks flows downwards and the molten metal in the valleys flows upwards, as the large curvature surface is eliminated, The metal flow direction gradually changes to be dominated by

Marangoni convection so that the liquid on the fluid surface moves from the hot end to the cold end, and then returns from the bottom of the liquid layer to the hot end. This also indicates that the temperature of the upper part of the fluid is higher than the temperature of the bottom of the fluid, and the temperature gradient in the vertical direction of the molten pool is opposite to the direction of gravitational acceleration [35-36]. Convection dominates the redistribution of molten metal, eventually smoothing the surface. As the temperature increases, the velocity distribution is radially outward. The flow from the center to the edge redistributes the molten material to form a relatively flat surface, as shown in Figure 5(d). The results show that the magnitude of the velocity field ranges from $10-4 \mathrm{~m} / \mathrm{s}$ to $0.8 \mathrm{~m} / \mathrm{s}$.

Laser energy density (ED) is related to laser power and scanning speed, and the specific calculation formula is as follows [37]: 


$$
\mathrm{ED}=k \frac{P}{v_{f} \cdot D}
$$

Where $k$ is the reference coefficient, $P$ is the laser power, $v_{f}$ is the scanning speed, and $D$ is the spot diameter.

Converting the simulated data into a line graph is shown in Figure 6 and Figure 7. The following conclusions can be drawn:

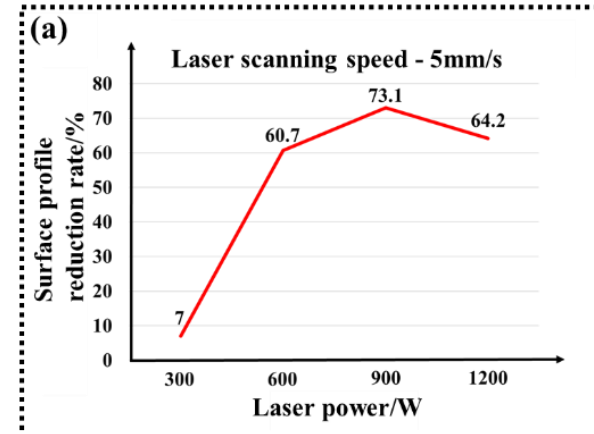

$(c)$

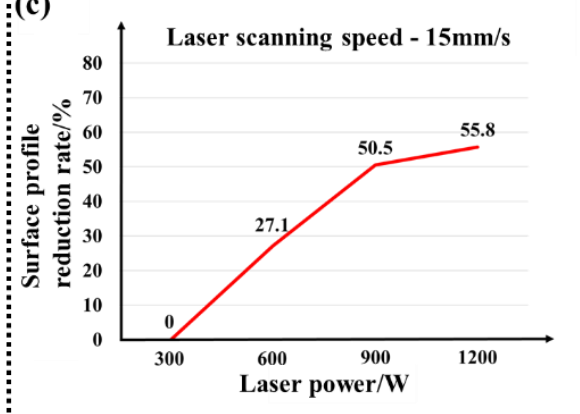

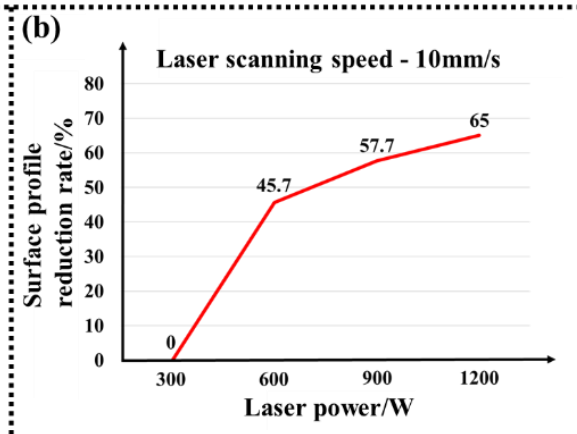

(d)

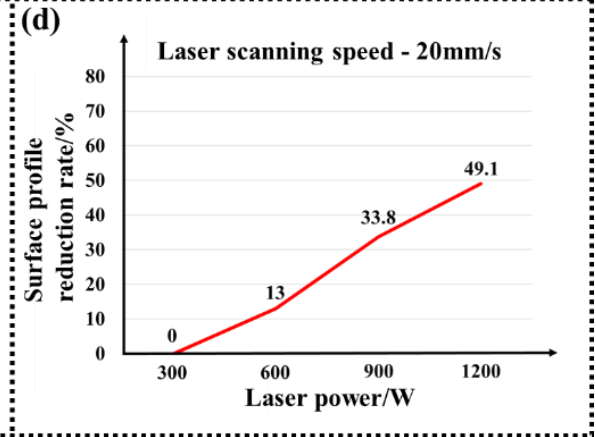

Figure 6 Variation of the reduction rate of surface profile with laser power under simulation conditions
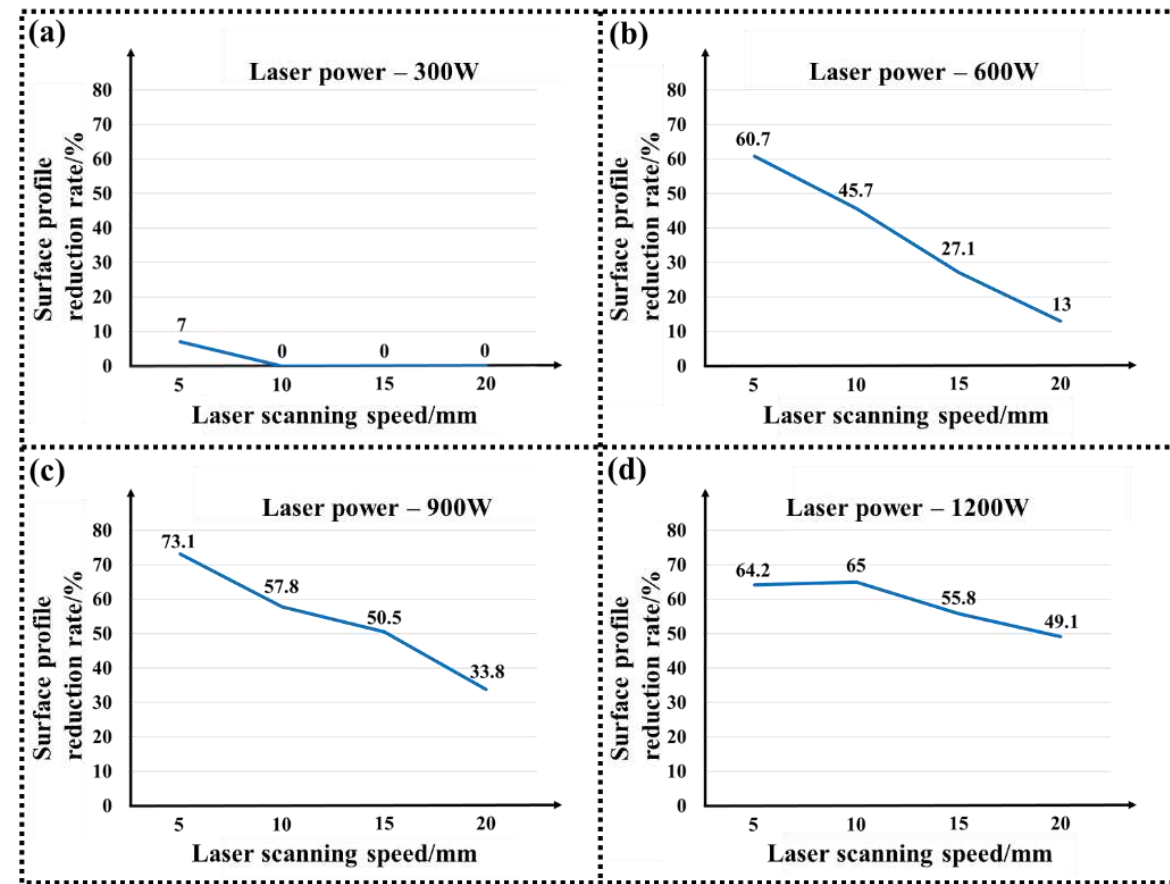

Figure 7 Variation of the reduction rate of surface profile with laser scanning speed under simulation conditions 
(1)When the laser power is $300 \mathrm{~W}$ and the laser scanning speed is $10 \mathrm{~mm} / \mathrm{s}, 15 \mathrm{~mm} / \mathrm{s}, 20 \mathrm{~mm} / \mathrm{s}$, the reduction rate of surface profile before and after remelting is 0 , which indicates that the laser energy density under this parameter group state is not enough to reduce The substrate melts, so the surface morphology of the substrate remains unchanged after remelting;

(2)When the laser scanning speed is $10 \mathrm{~mm} / \mathrm{s}, 15 \mathrm{~mm} / \mathrm{s}, 20 \mathrm{~mm} / \mathrm{s}$, as the laser power increases, the laser energy density gradually increases. As shown in Figure 6 and Figure 7, the area of the laser can melt the substrate also When the laser power is $300 \mathrm{~W}, 600 \mathrm{~W}, 900 \mathrm{~W}$, the laser energy density gradually decreases as the laser scanning speed increases, so the surface profile decreases. The rate of negative correlation is gradually decreasing;

(3)When the laser power is $1200 \mathrm{~W}$ and the scanning speed is $5 \mathrm{~mm} / \mathrm{s}$, the reduction rate of the surface profile by laser remelting is lower than the $900 \mathrm{~W}-5 \mathrm{~mm} / \mathrm{s}$ and $1200 \mathrm{~W}-10 \mathrm{~mm} / \mathrm{s}$ parameter groups. This is because the laser energy density is too large, such as As shown in Figure 8, after the laser completely melts the convex peaks, due to the continuous action of the Marangoni effect, the ends of the molten pool gradually rise, which reduces the reduction rate of surface profile.

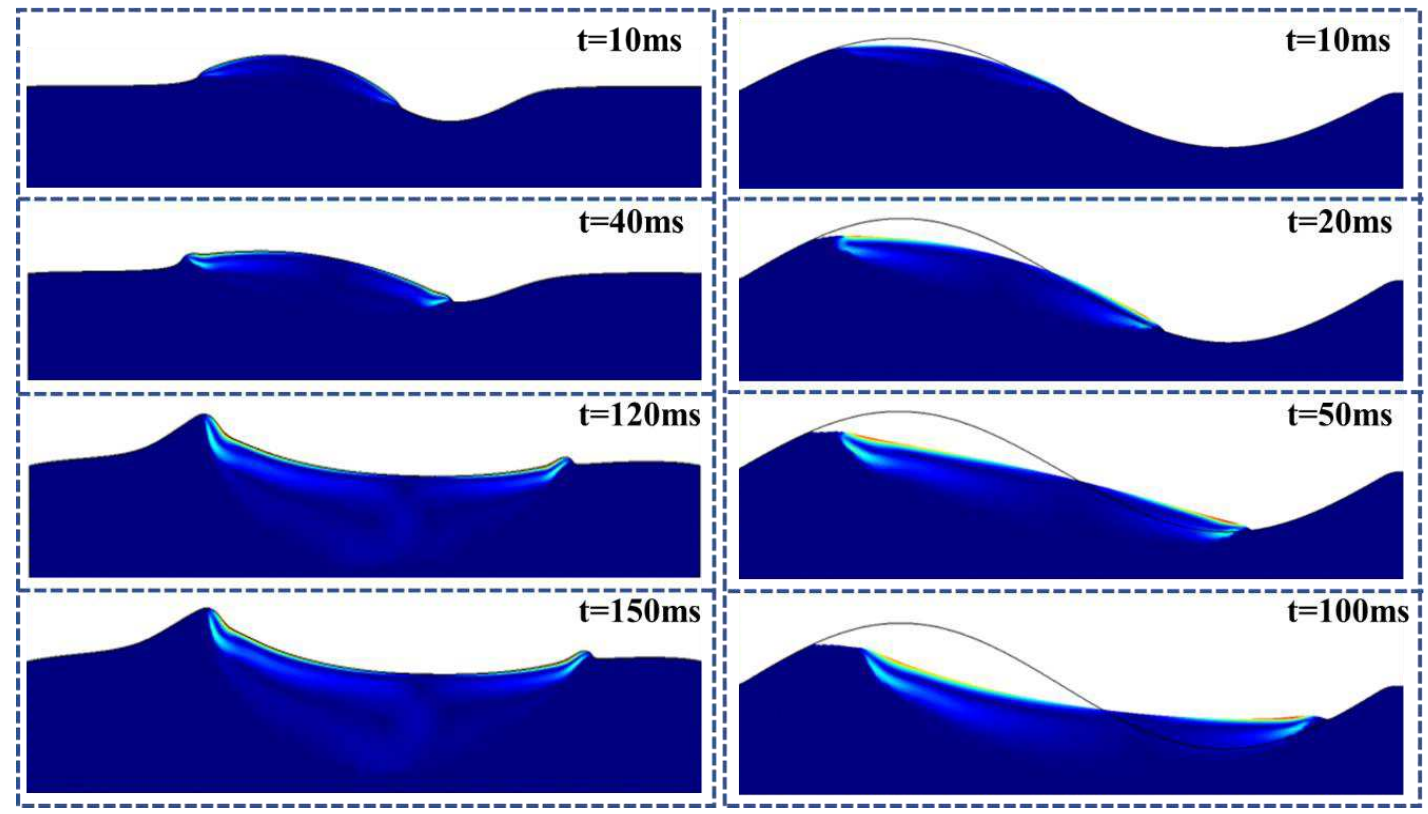

(a) $1200 \mathrm{~W}-5 \mathrm{~mm} \cdot \mathrm{s}^{-1}$

(b) $600 \mathrm{~W}-20 \mathrm{~mm} \cdot \mathrm{s}^{-1}$

Figure 8 Simulate the laser remelting process of different laser power-scanning speed parameter groups

\section{Experiment and result}

\subsection{Experiment preparation}

\subsubsection{Experimental materials}

The chemical composition of the $316 \mathrm{~L}$ stainless steel welding wire material and powder material used in the experiment is shown in Table 3. The substrate used for welding is 304 stainless steel plate, the size of the substrate is $200 \times 200 \times 30 \mathrm{~mm}$, and alcohol scrubbing is used before the experiment. 
Table 3 chemical composition of $316 \mathrm{~L}$ stainless steel wire and powder (mass fraction, \%)

\begin{tabular}{cccccccccc}
\hline & $\mathrm{Cr}$ & $\mathrm{Mn}$ & $\mathrm{Mo}$ & $\mathrm{Ni}$ & $\mathrm{Si}$ & $\mathrm{C}$ & $\mathrm{P}$ & $\mathrm{S}$ & $\mathrm{Fe}$ \\
\hline Wire & 19.06 & 2.06 & 2.20 & 12.74 & 0.53 & 0.025 & 0.021 & 0.011 & $\mathrm{Bal}$ \\
Powder & 16.28 & 0.88 & 2.00 & 9.86 & 0.54 & 0.050 & 0.034 & 0.062 & $\mathrm{Bal}$ \\
\hline
\end{tabular}

\subsubsection{Experimental equipment}

The CMT forming volume of 316L stainless steel parts is prepared by welding robot forming system, and the welding machine uses the Fronius CMT Advanced 4000 welding power source, as shown in Figure 9.

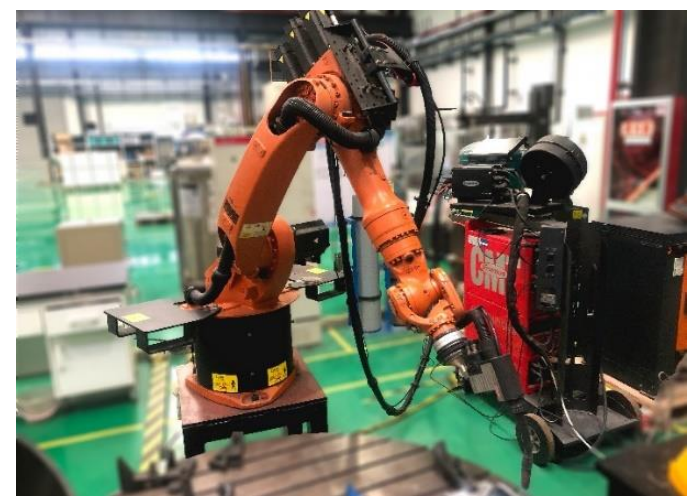

Figure 9 Cold metal transfer (CMT) equipment

The wire grade of the wire feeder is ER316L, the diameter of the wire is $1.2 \mathrm{~mm}$, and the shielding gas is $98 \% \mathrm{Ar}+2 \% \mathrm{O}_{2}$ gas. Other main process parameters are obtained through preliminary process experiments, as shown in Table 4.

Table 4 Main process parameters of $316 \mathrm{~L}$ stainless steel parts formed by CMT

\begin{tabular}{ccccc}
\hline $\begin{array}{c}\text { Wire feeding speed } \\
/\left(\mathrm{m}_{\mathrm{min}} \mathrm{m}^{-1}\right)\end{array}$ & $\begin{array}{c}\text { Welding speed } \\
/\left(\mathrm{m}_{\mathrm{min}}^{-1}\right)\end{array}$ & $\begin{array}{c}\text { Dry elongation } \\
/ \mathrm{mm}\end{array}$ & $\begin{array}{c}\text { Gas flow rate } \\
/\left(\mathrm{L} . \mathrm{min}^{-1}\right)\end{array}$ & $\begin{array}{c}\text { Overlap rate } \\
/ \%\end{array}$ \\
\hline 6.5 & 0.5 & 15 & 20 & 30 \\
\hline
\end{tabular}

The LMD forming volume of 316L stainless steel parts is prepared by a 3-axis CNC machine, using argon gas (99.999\%) for partial atmosphere protection of the cladding, equipped with a fiber laser, with a maximum output power of $2 \mathrm{~kW}$, equipped with a coaxial powder feeding cladding head, as shown in Figure 10.

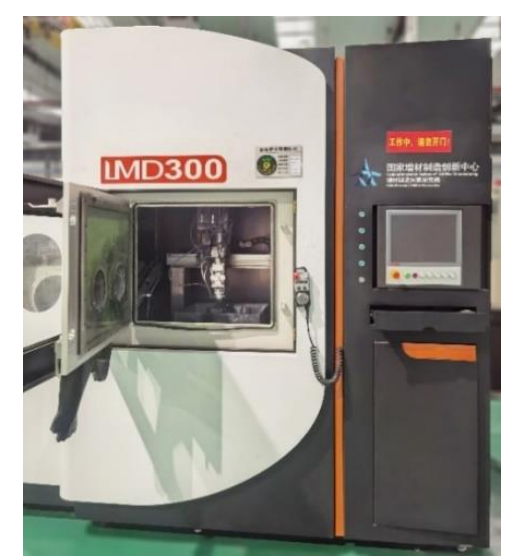

Figure 10 Laser metal deposition (LMD) equipment 
The defocus of the cladding head used in laser additive manufacturing is $14.5 \mathrm{~mm}$, and the spot diameter is about $2.5 \mathrm{~mm}$. The distance between the bottom of the nozzle of the cladding head and the substrate is $10 \mathrm{~mm}$. Other main process parameters are obtained through preliminary process experiments, as shown in Table 5.

Table 5 The main process parameters of LMD forming 316L stainless steel parts

\begin{tabular}{ccccc}
\hline $\begin{array}{c}\text { Laser power } \\
/ \mathrm{W}\end{array}$ & $\begin{array}{c}\text { Scan speed } \\
\left(\left(\mathrm{mm} \cdot \mathrm{min}^{-1}\right)\right.\end{array}$ & $\begin{array}{c}\text { Powder feeding speed } \\
/\left(\mathrm{g} \cdot \mathrm{min}^{-1}\right)\end{array}$ & $\begin{array}{c}\text { Spot diameter } \\
/ \mathrm{mm}\end{array}$ & $\begin{array}{c}\text { Overlap rate } \\
/ \%\end{array}$ \\
\hline 900 & 360 & 8.10 & 2.5 & 40 \\
\hline
\end{tabular}

\subsubsection{Experimental program}

Refer to the basic process parameters in the remelting simulation process, design the corresponding laser power and scanning speed to perform laser remelting verification experiments on the CMT forming substrate surface. Remelt a $25 \times 20 \mathrm{~mm}$ square area with each set of parameter, and use a dial indicator to measure the remelting surface profile. The surface height difference in each square area before and after remelting is calculated, the surface profile reduction rate $\mathrm{c}$ respect to each parameter is calculated, and the calculation formula of the profile reduction rate $c$ is defined as follows:

$$
c=\frac{\Delta h_{1}-\Delta h_{2}}{\Delta h_{1}} \times 100 \%
$$

Among them, $\Delta h_{1}$ is the maximum surface height difference before remelting, and $\Delta h_{2}$ is the maximum surface height difference after remelting.

(1) Metallographic preparation

The metallographic samples of the LMD forming volume, the CMT forming volume and the bonding area of the CMT-LMD hybrid forming are prepared, and then they are embedded in the inlay machine after ultrasonic cleaning. Use 240\# 2000\# metallographic sand for polishing and $3.5 \mu \mathrm{m}$ diamond spray polishing agent for polishing. The 316 L stainless steel corrosive solution uses $10 \mathrm{gFeCL}_{3}+30 \mathrm{mlHCL}+120 \mathrm{mlH}_{2} \mathrm{O}$, and the metallographic structure is observed under an optical microscope.

(2) Shear test

Three $40 \times 20 \times 20 \mathrm{~mm}$ experimental sample substrates are formed by CMT, which surfaces are respectively threated by three different methods, includings non-treatment, laser remelting, and milling, then based on the surface of each sample substrate, blocks with size of $30 \times 15 \times 18 \mathrm{~mm}$ are formed by LMD. Taking the joint interface as the center line, three sets of shear test rod are prepared, and the size of the test rod is shown in Figure 11(a) below, and the sampling position of the test rods is shown in Figure 11(b). 


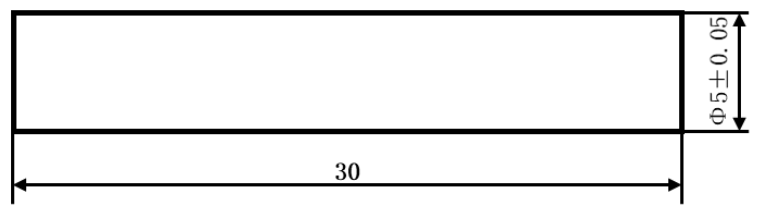

(a)

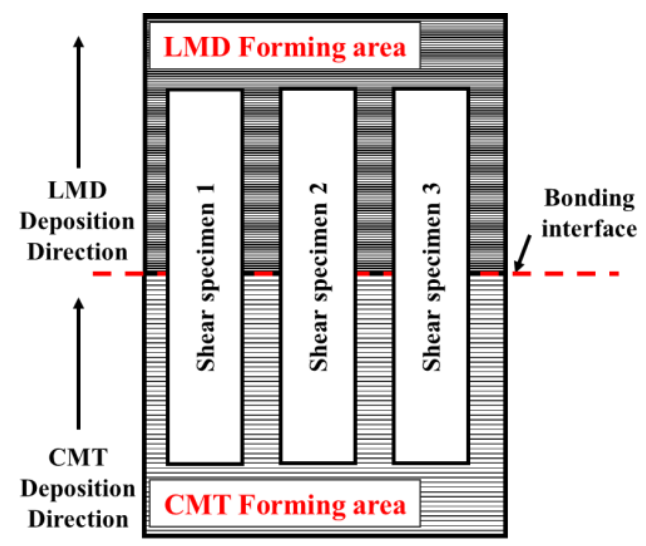

(b)

Figure 11 (a) Basic dimensions of the shear test bar;(b) Sketch map of the sampling position of the shear test bar

\subsection{Experimental results}

In order to verify the accuracy of the above-mentioned laser remelting simulation results, a study on the influence of laser power and scanning speed on the surface profile of the wire was carried out. The height difference between the highest point and the lowest point on the surface of each area was used as the evaluation of the surface profile. Indicators, the height difference of each area before and after remelting was measured by a dial indicator, and the intuitive cladding effect is shown in Figure 12.

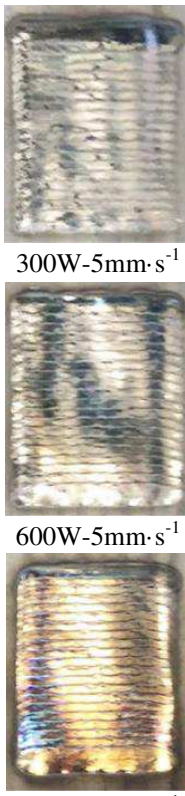

$900 \mathrm{~W}-5 \mathrm{~mm} \cdot \mathrm{s}^{-1}$

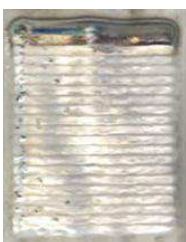

$300 \mathrm{~W}-10 \mathrm{~mm} \cdot \mathrm{s}^{-1}$

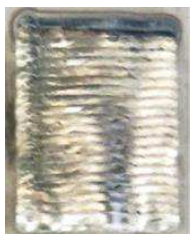

$600 \mathrm{~W}-10 \mathrm{~mm} \cdot \mathrm{s}^{-1}$

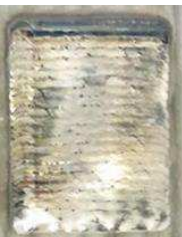

$900 \mathrm{~W}-10 \mathrm{~mm} \cdot \mathrm{s}^{-1}$

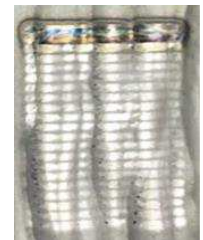

$300 \mathrm{~W}-15 \mathrm{~mm} \cdot \mathrm{s}^{-1}$

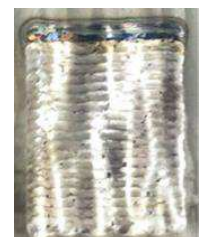

$600 \mathrm{~W}-15 \mathrm{~mm} \cdot \mathrm{s}^{-1}$

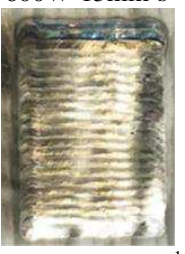

$900 \mathrm{~W}-15 \mathrm{~mm} \cdot \mathrm{s}^{-1}$

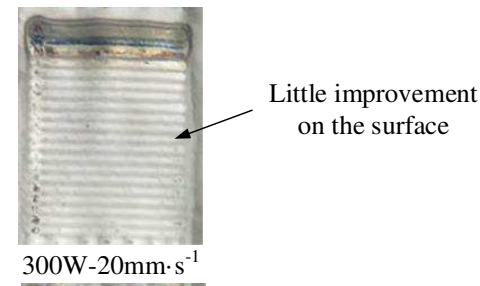

$300 \mathrm{~W}-20 \mathrm{~mm} \cdot \mathrm{s}^{-1}$

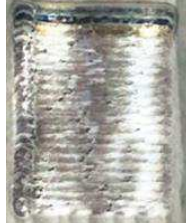

600W-20mm $\cdot \mathrm{s}^{-1}$

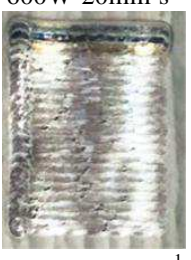

$900 \mathrm{~W}-20 \mathrm{~mm} \cdot \mathrm{s}^{-1}$

Figure 12 Actual laser remelting effect diagram corresponding to different laser power and scanning speed 

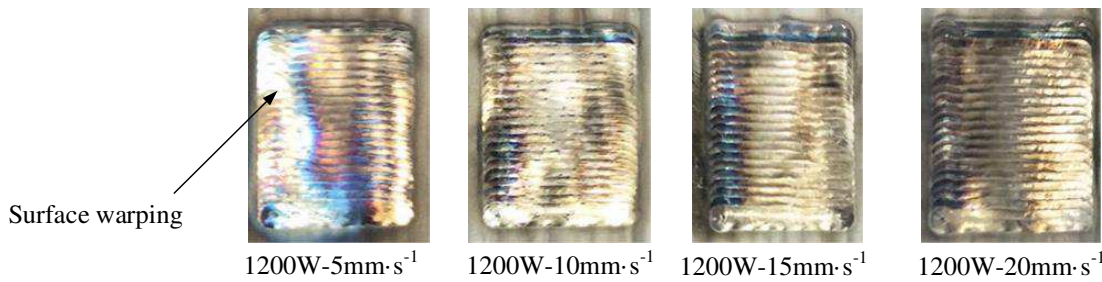

$1200 \mathrm{~W}-10 \mathrm{~mm} \cdot \mathrm{s}^{-1} \quad 1200 \mathrm{~W}-15 \mathrm{~mm} \cdot \mathrm{s}^{-1}$

$1200 \mathrm{~W}-20 \mathrm{~mm} \cdot \mathrm{s}^{-1}$

Figure 12 (continued) Actual laser remelting effect diagram corresponding to different laser power and scanning speed

According to the measured data, it is converted into a line chart as shown in Figure 13 and Figure 14 below. It can be seen that the actual improvement trend of the laser remelting of each parameter group on the surface profile of each area is close to the simulation result, and the error of the flatness reduction rate of the corresponding parameter group is within the range of about $20 \%$. The main reasons are:

(1)The actual laser heat source is similar to Gaussian distribution, not regular Gaussian distribution;

(2)There is a big gap between actual heat convection and heat conduction and theoretical heat convection and heat conduction.

According to process experience, the reduction rate of surface profile needs to be at least $55 \%$ or more. It can be seen from Figure 13 and Figure 14 that there are parameters that meet the optimization requirements in the actual laser remelting process parameter group. Therefore, it is proved that the flatness of the CMT forming surface can be achieved by laser remelting. The method required for LMD forming is feasible.

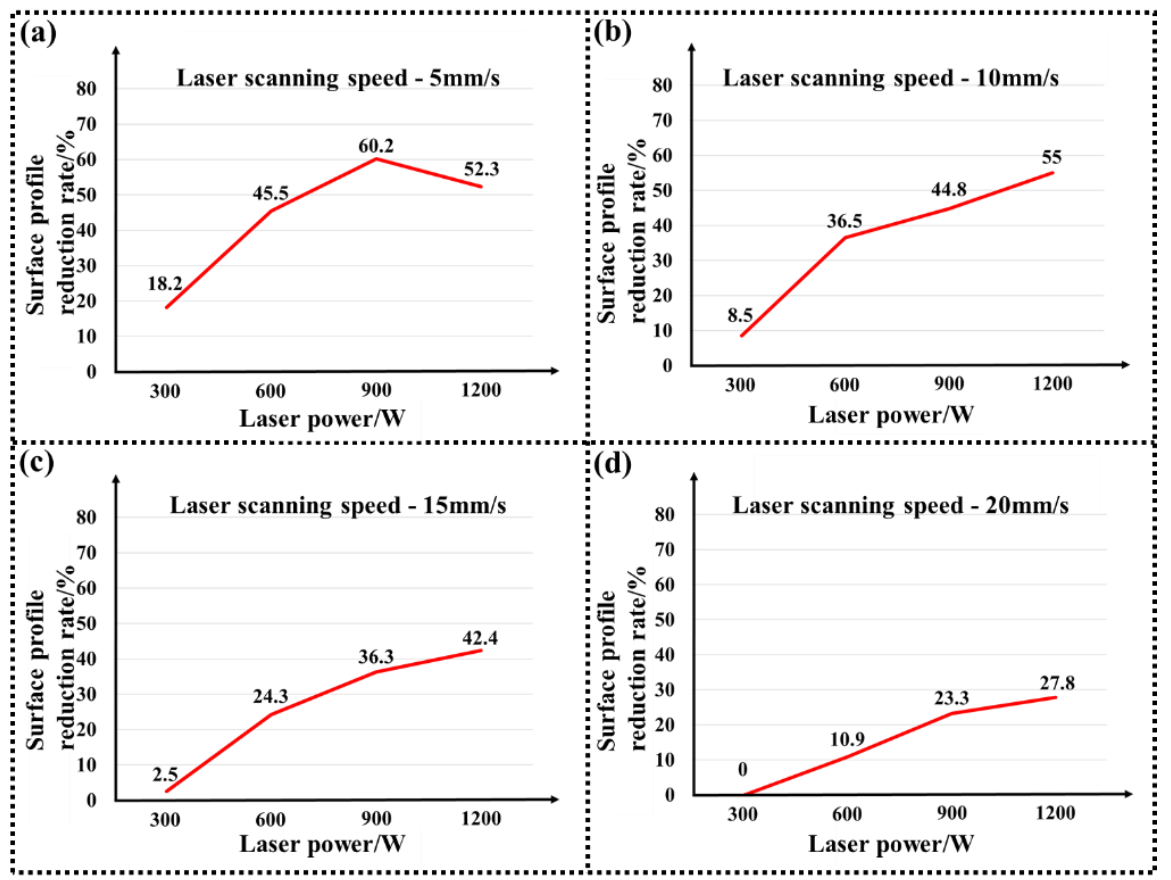

Figure 13 Variation of the reduction rate of surface profile with laser power under actual experimental conditions 

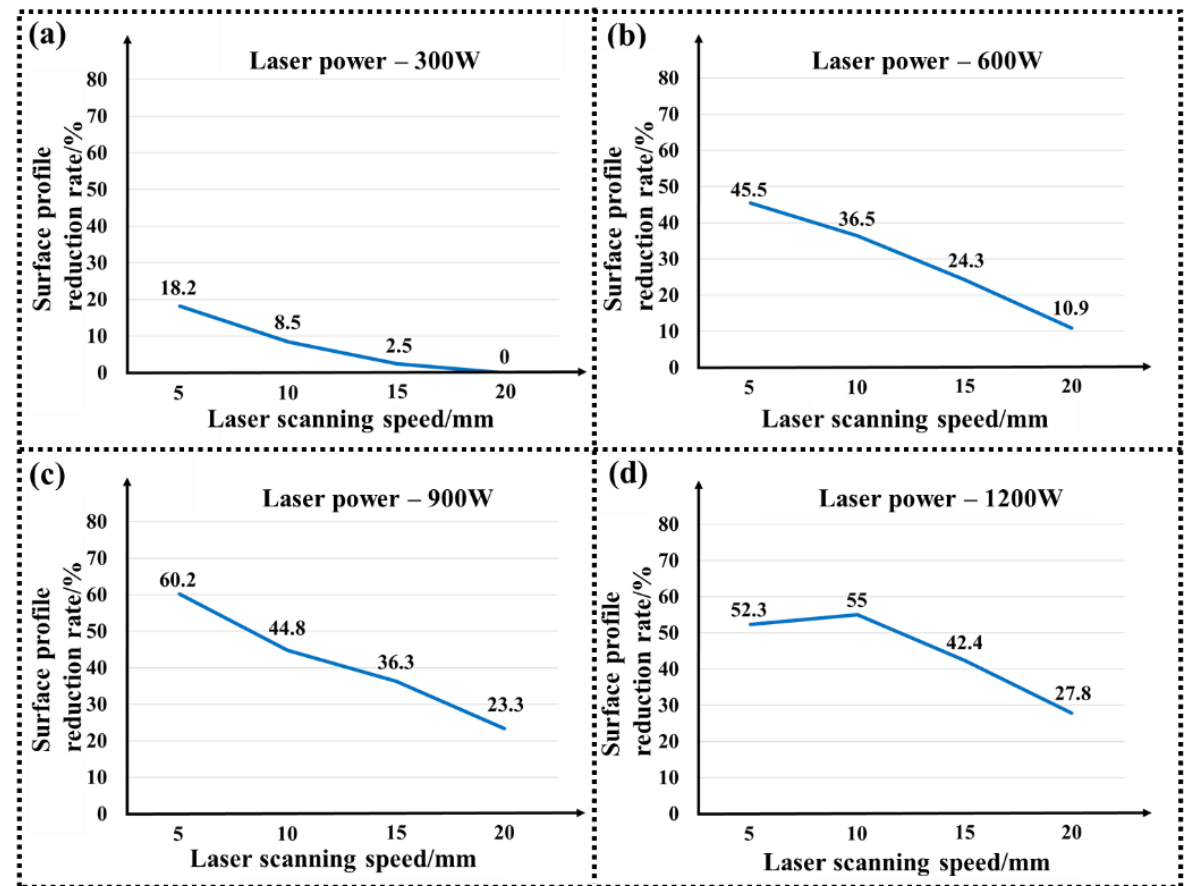

Figure 14 Variation of the reduction rate of surface profile with laser scanning speed under actual experimental conditions

\subsection{Microstructure analysis}

Three kinds of substrates were obtained by remelting, milling and unremelting the forming surface of CMT, and LMD forming was performed on the surface after treatment, and metallographic samples were prepared at the bonding interface. The study of the mechanical behavior of materials must consider the influence of the interface and grain boundaries [38-39]. The metallographic structure is shown in Figure 15. It is found that the formed structures of the two processes are composed of $\delta$ ferrite $+\gamma$ austenite, but in the CMT formed structure area, the dendrite spacing and grain size are larger than the LMD forming structure area, mainly due to the difference of the raw material composition and thermal history in the forming process of the two processes [3]. Because the dendrite spacing and grains of the LMD region are smaller, there are more grains and grain boundaries in the unit area. When external load is applied, the load and deformation can be distributed to more grains, which can It can better suppress the "slip" of atoms inside the grain, so the mechanical properties of the LMD forming area are better than the CMT forming area. And through observation, it was found that after cladding the surface of the remelted substrate, no remelted layer was found at the bonding interface. This is because the subsequent LMD cladding process completely covered it, and the bonding after remelting The morphology of the interface at the interface is similar to the bonding interface formed after milling, while Due to the uneven surface of the substrate, the growth direction of the microstructure formed by LMD is inconsistent with the growth direction of the structure formed by CMT, and there is a certain angle deviation. 

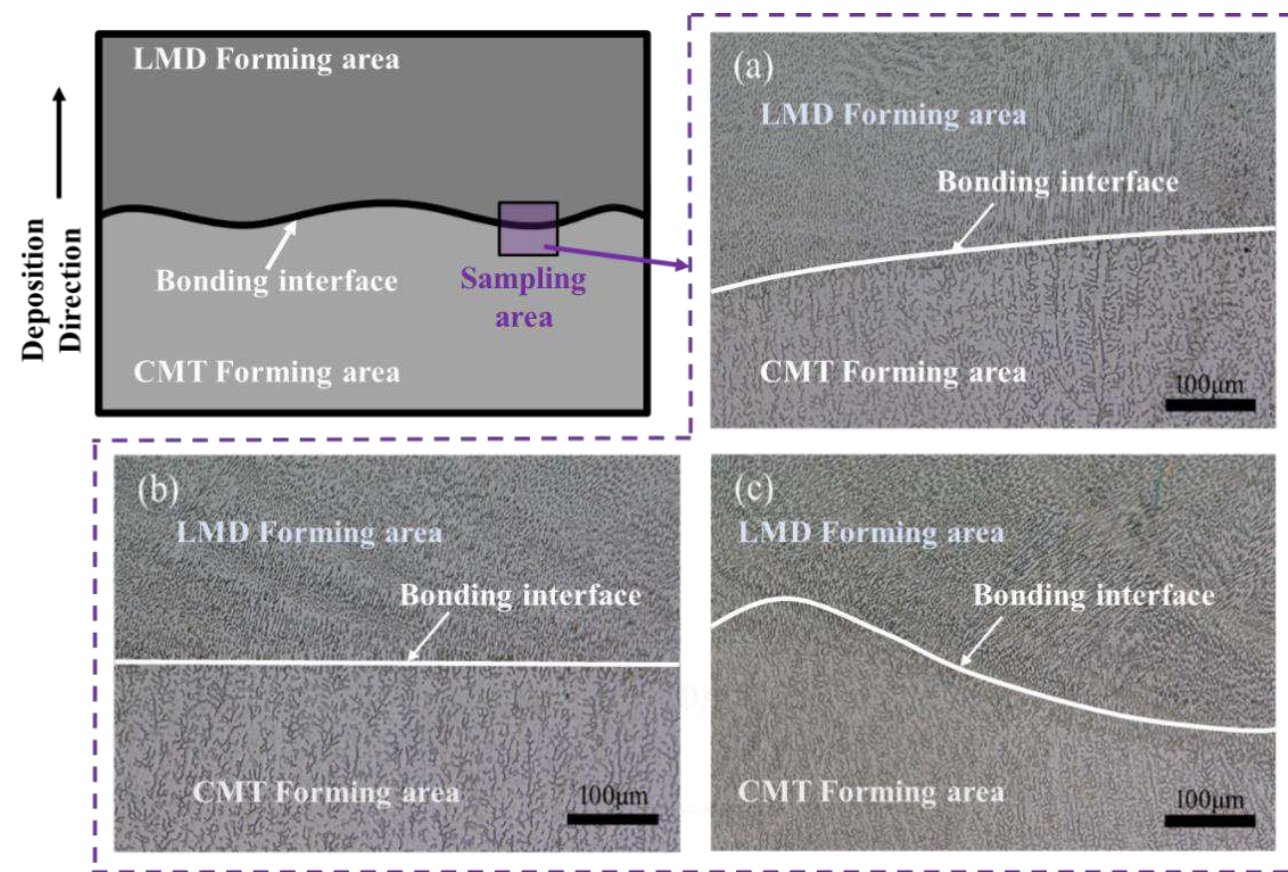

Figure 15 The microstructure of the bonding interface under a 500× microscope: (a) Bonding

interface after surface remelting treatment; (b) Bonding interface after surface milling treatment;

(c) Untreated bonding interface on the surface

\subsection{Shear performance analysis}

The corresponding shear test results of the shear samples prepared for different substrate bonding interfaces are shown in Figure 16 below. It can be seen that the non-remelted shear strength is slightly lower than the shear performance at the bonding interface after laser remelting or milling. This is because the shearing direction is along the $\mathrm{X}$-axis, and when the shearing direction is When the direction is perpendicular, the number of grain boundaries on the shear interface is the largest, so the shear resistance is the best, while the non-remelted bonding interface has a disorderly growth direction and is at a certain angle with the direction of the shear interface, so the grain in the shear section The number of boundaries is small, and when loaded, the ability to inhibit the "slip" of the atoms inside the grain is weakened, and the shear resistance is also reduced.

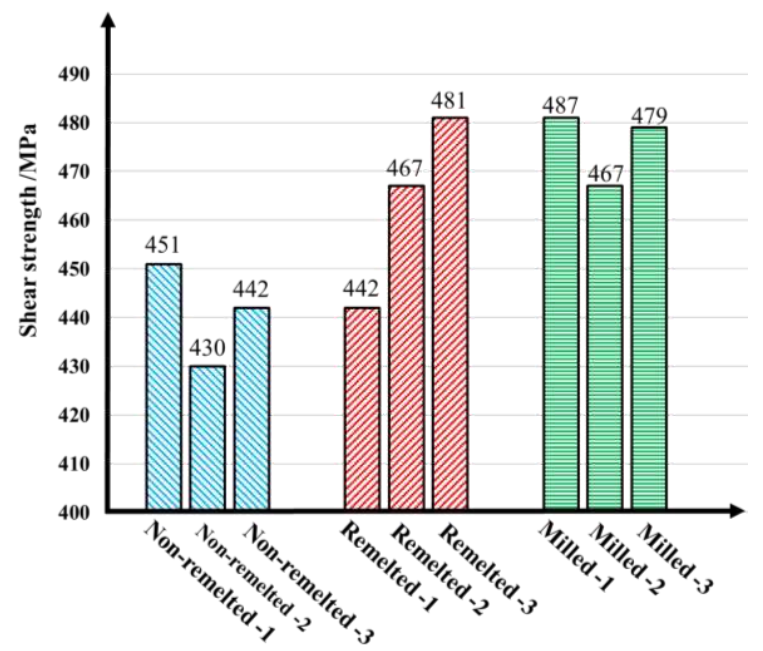

Figure 16 Different interface processing methods corresponding to the bonding interface shear performance 


\section{Conclusion}

(1) When the scanning speed is constant, as the laser power increases, the improvement degree of laser remelting on the surface profile of the CMT forming substrate first increases and then decreases; and when the laser power is constant, As the scanning speed increases, the improvement of the surface profile of the CMT forming substrate by laser remelting gradually decreases, but when the laser power is $1200 \mathrm{~W}$ and the scanning speed is $5 \mathrm{~mm} / \mathrm{s}$, the improvement of the surface profile is less than $10 \mathrm{~mm} / \mathrm{s}$. This is because the laser energy density is too large, leading to the continuous action of the Marangoni effect.

(2) The dendrite spacing and grain size of the CMT forming structure are larger than the LMD forming structure area, and when the surface of the CMT forming substrate is not treated, the dendrite growth direction of the structure at the bonding interface is disordered, but when the CMT forming substrate surface After milling or laser remelting, the growth direction of LMD dendrite at the bonding interface is close to the same as that of CMT.

(3) When the surface of the CMT forming substrate is not processed, the LMD forming is directly performed, and the shear strength at the bonding interface obtained is slightly lower than that of the surface of the CMT forming substrate after milling or laser remelting, and then LMD forming, The resulting bonding interface is mainly due to the disordered growth direction of the dendrite, which is at a certain angle with the shear interface, so that the number of grain boundaries in the shear interface is relatively reduced, and the ability to inhibit the "slip" of atoms inside the grain is relatively Weakened, so the shear resistance is also reduced.

\section{Availability of data and material}

All the data have been presented in the manuscript.

\section{Funding}

This work is financially supported by the Projects of National Natural Science Foundation of China (51605373)

\section{Contributions}

Fei Xue and Xin Cui conceived and designed the research, Xin Cui wrote the paper, Longfei Zheng directed the actual experiment, Mian Li directed the simulation analysis, Xue Fei and Xuewei Fang also reviewed the article.

\section{Ethics declarations}

\section{Ethical approval}

Not applicable. 


\section{Consent to participate}

The authors declare that they all consent to participate in this research.

\section{Consent to publish}

The authors declare that they all consent to publish the manuscript.

\section{Competing interests}

The authors declare no competing interests.

\section{References}

[1] Xuewei Fang,Lijuan Zhang,Guopeng Chen,et al. Microstructure evolution of wire-arc additively manufactured 2319 aluminum alloy with interlayer hammering[J].Materials Science \& Engineering A,2021,800:140168-1-140168-11.

[2] Xuewei Fang,Hui Li b,Xiaoge Li b,et al. Effect of post heat treatment on the microstructure and mechanical properties of wire-arc additively manufactured A357 alloy components[J]. Materials Letters,2020,269: 127674-1-127674-4.

[3] Xiao Hui. Research on the control and mechanism of the solidification structure of Inconel_718 alloy by laser additive manufacturing [D]. Changsha: Hunan University, 2017.

[4] Tascioglu, E., Karabulut,et al.Influence of heat treatment temperature on the microstructural, mechanical, and wear behavior of 316L stainless steel fabricated by laser powder bed additive manufacturing[J]. Int J Adv Manuf Technol,2020,107: 1947-1956.

[5] Kannan, A.R., Shanmugam,et al. Effect of cold metal transfer process parameters on microstructural evolution and mechanical properties of AISI 316L tailor welded blanks[J].Int J Adv Manuf Technol,2019,103:4265-4282.

[6] Kim, T., Ha,et al. Analysis of residual stress evolution during powder bed fusionprocess of AISI 316L stainless steel with experiment and numerical modeling[J]. Int $\mathrm{J}$ Adv Manuf Technol,2019,105:309-323.

[7] Hammar O, Svensson U. Influence of steel composition on segregation and microstructure during solidification of austenitic stainless steels[C]. Solidification and Casting of Metals. 1977:401-410.

[8] He Lihua. Research on the structure and properties of welding rapid forming 316L stainless steel [D]. Nanchang: Nanchang Hangkong University,2015.

[9] Wang Xiaoguang, Liu Fencheng, Fang Ping. Analysis of forming accuracy and microstructure and performance of $316 \mathrm{~L}$ stainless steel by CMT arc additive manufacturing[J]. Transactions of the China Welding Institution,2019,40(5):100-106.

[10] He Lihua. Research on the microstructure and properties of welding rapid prototyping 316L stainless steel [D]. Nanchang: Nanchang Hangkong University,2015. 
[11] Jia Wenpeng, Tang Huiping, He Weiwei, et al. Microstructure simulation of 316L stainless steel rapid laser forming[J]. Acta Metall Sinica,2010,46(02):135-140.

[12] Lin Xin, Yang Haiou, Chen Jing, et al. Evolution of 316L stainless steel microstructure during laser rapid prototyping[J]. Acta Metall Sinica,2006,42(4):361-368.

[13] Wang Pei, Li Zhengxian, Huang Chunliang, et al. Application research of laser surface modification technology on titanium alloy[J]. Laser Journal,2014,35(02):4-6.

[14] Bordatchev, E.V., Hafiz, et al. Performance of laser polishing in finishing of metallic surfaces[J]. Int J Adv Manuf Technol,2014,73:35-52.

[15] Meng Yunlong, Yang Jiaoxi, Zhang Jianjian, et al. The effect of laser remelting on the microstructure and properties of Aermet100 steel[J]. Progress in Laser and Optoelectronics,2018, $55(2): 1-8$

[16] Gao Yali, Ma Guangchao, Zhang Haibo, et al. Corrosion resistance and biocompatibility of laser remelted layer of AZ91HP magnesium alloy[J]. Journal of Materials and Heat Treatment,2015, 36(1):147-152.

[17] Wang Yuanmi. The effect of laser remelting on the microstructure and mechanical properties of 304 austenitic stainless steel [D]. Hengyang, Hunan: University of Nanhua,2013.

[18] YAO Y,LI X WANG YY,et al. Microstructural evolution and mechanical properties of Ti-Zr beta titanium alloy after laser surface remelting[J]. Journal of Alloys and Compounds,2014,583(2):43-47 .

[19] Majumdar JD, Galun R, Mordike BL, et al. Effect of laser surface melting on corrosion and wear resistance of a commercial magnesium alloy[J].Material Science \& Engineering,2003,A361(12):119- 129 .

[20] Zhang Qingmao, Liu Wenjin. Study on the structure and tribological properties of laser fused layer[J]. Power Laser and Particle Beam,2006,18(3):389-392.

[21] Builder G. Electrochemical investigation of the influence of laser surface melting on the microstructure and corrosion behavior of ZE41 magnesium alloy - An EIS based study[J].Corrosion Science,2011,53(4):1505-1514.

[22] Zhang Z, Lin P, Ren L.Wear resistance of AZ91D magnesium alloy processed by improved laser surface remelting[J].Optics \& Laser in Engneering,2014,55(7):237-242.

[23] Han, Q., Jiao,et al.Effect of heat treatment and laser surface remelting on AlSi10Mg alloy fabricated by selective laser melting[J].Int J Adv Manuf Technol,2019,102:3315-3324.

[24] Courtois M, Carin M, Masson PL, et al. A two-dimensional axially-symmetric model of keyhole and melt pool dynamics during spot laser welding[J]. Revue De Metallurgie Cahiers Dinformations Techniques,2013,110(2):165-173.

[25] Chen Xiaofeng. Simulation study on the transient formation process of thin and long holes in thick plates by laser deep penetration welding[D]. Changsha: Master's degree thesis of Hunan University,2014. 
[26] Huang Ting. Numerical simulation and experimental research of laser texturing forming process[D]. Jiangsu University,2019.

[27] Lu S, Fujii H, Nogi K. Marangoni convection and weld shape variations in Ar-O2, and ArCO2,shielded GTA welding[J]. Materials Science \& Engineering A,2004,380(1-2):290-297.

[28] Zhang Y, Li S, Chen G, et al. Experimental observation and simulation of keyhole dynamics during laser drilling[J]. Optics \& Laser Technology, 2013, 48:405-414.

[29] Pang S, Chen X, Zhou J, et al. 3D transient multiphase model for keyhole, vapor plume, and weld pool dynamics in laser welding including the ambient pressure effect[J]. Optics and Lasers in Engineering,2015,74:47-58.

[30] Zhang Y,Li S,Chen G,et al.Experimental observation and simulation of keyhole dynamics during laser drilling[J]. Optics \& Laser Technology,2013,48:405-414.

[31] Chi Zhang, Jing Zhou, Hong Shen. Role of Capillary and Thermocapillary Forces in Laser Polishing of Metals[J]. Journal of Manufacturing Science and Engineering,2016,139(4):041019-1041019-11.

[32] Masson P L, Courtois M, Carin M, et al. A complete model of keyhole and melt pool dynamics to analyze instabilities and collapse during laser welding[J]. Journal of Laser Applications,2014,26(4):042001.

[33] Tyler L. Perry, Dirk Werschmoeller, Neil A. Duffie, et al. Examination of Selective Pulsed Laser Micropolishing on Microfabricated Nickel Samples Using Spatial Frequency Analysis[J]. Journal of Manufacturing Science and Engineering,2009,131:021002- 1-021002-9.

[34] Zou Guowen. Numerical simulation and experimental research on the forming mechanism of laser texturing [D]. Zhenjiang: Jiangsu University,2018.

[35] Kang Q, Duan L, Hu W R. Experimental study of surface deformation and flow pattern on Buoyant-thermocapillary convection.Microgravity[J]. Science\&Technology,2004,15(2):18-24.

[36] Duan Li, Kang Qi, Hu Wenrui. Free surface characteristics of thermocapillary convection[J]. Science in China Series E Technical Science,2006,36(11):1335-1343.

[37] UkarE, LamikizA, López de LacalleL.N, et al. Laser polishing of tool steel with CO laser and high-power diode laser[J]. International Journal of Machine Tools and Manufacture,2010,50(1):115 -125 .

[38] K. E. Aifantis. Interfaces in crystalline materials[J]. Procedia Engineering.2009:167-170.

[39] K. E. Aifantis, A. A. Konstantinidis. Hall-Petch revisited at the nanoscale[J]. Materials Science and Engineering: B.2009,163(3):139-144. 